\title{
Sesamin attenuates neuronal damage through inhibition of microglial activation following global cerebral ischemia in rats
}

\author{
Minjung Kong ${ }^{1 \#}$, Sung In Hong ${ }^{1,2^{*}}$ \\ 1: Department of Herbal Pharmacology, College of Oriental Medicine, Kyung Hee University, Seoul, Korea \\ 2 : Department of East-West Integrated Medicine, Kyung Hee University Medical Center, Seoul, Korea
}

\begin{abstract}
Objectives : Sesamin, a major lignan in sesame seeds, has been reported to have neuroprotective effects against in vitro ischemia and in vivo MCAo-reperfusion cerebral ischemia model, however, there is no reports in an in vivo global cerebral ischemia model. The purpose of the study was to investigate the neuroprotective effect of sesamin in global cerebral ischemia induced by four-vessel occlusion (4-VO) in rats through inhibition of microglial activation in this model.

Methods : The neuroprotective effects were investigated using a $10 \mathrm{~min}$ of $4-\mathrm{VO}$ ischemia rat model by measuring intact pyramidal neurons in the CA1 region of the hippocampus using Nissle staining. The antiinflammatory or reducing neurotoxicity effect was investigated using immunohistochemisty, RT-PCR and western blot analysis of inflammatory or neurotoxic mediators.

Results : Intraperitoneal injection of sesamin at doses of $0.3,1.0,3.0$, and $10.0 \mathrm{mg} / \mathrm{kg}$ at $0 \mathrm{~min}$ and $90 \mathrm{~min}$ after ischemia conferred $26.6 \%, 30.1 \%, 42.5 \%$, and $30.5 \%$ neuroprotection, respectively, compared to the vehicle-treated control group. A $3.0 \mathrm{mg} / \mathrm{kg}$ dose of sesamin inhibited microglia activation and consequently, cyclooxygenase -2 , inducible nitric oxide, and interleukine $-1 \beta$ expressions at $48 \mathrm{~h}$ after reperfusion.

Conclusions : Sesamin protects neuronal cell death through inhibition of microglial activation or the production of neurotoxic metabolites and proinflammatory mediators by microglia such as COX -2 , iNOS and $\mathrm{IL}-1 \beta$ in global cerebral ischemia.
\end{abstract}

Key words : Sesamin, Global cerebral ischemia, 4-vessel occlusion, Microglial activation, Neuroprotection

\section{Introduction}

Sesame, an oilseed from the plant Sesamum indicum, is highly valued as a traditional herb and it may be a potent natural agent with both therapeutic applications and use in preventing human illness ${ }^{1)}$. Sesamin, a major lignan in sesame seeds, which comprises approximately $0.5 \%$ in sesame seeds ${ }^{2)}$, is assumed to play important roles in plant defense and has been frequently used as potent antioxidants ${ }^{3)}$.

Recently sesamin was reported to have the neuroprotective effect on focal cerebral ischemic damage $^{4)}$ and intracerebral hemorrhage in rats ${ }^{5)}$. This effect is attributed to its antioxidant, antiinflammatory properties ${ }^{6)}$ and inhibition of microglial activation in murine cell line ${ }^{5,7,8)}$. However, there is no report of sesamin on global cerebral ischemic injury, which is different from focal cerebral ischemia in that it occurs in serious cardiovascular disorders such as cardiac arrest, cardiogenic shock after myocardial infarction, or reversible severe hypotension ${ }^{9)}$.

Global cerebral ischemia involves a short very intense insult in which ATP is severely lowered. A histological hallmark of global ischemia is the selective and delayed neuronal loss in the pyramidal neurons and they are most vulnerable cells in loss of blood supply to the brain in the CA1 region of the

\footnotetext{
* Corresponding author : Sung In Hong, Department of Herbal Pharmacology, College of Oriental Medicine, Kyung Hee University, Seoul, Korea.

- Tel : +82-2-961-0419 · Fax: +82-2-964-0325 ·E-mail : sthong@khu.ac.kr

\# First author : Minjung Kong, Department of Herbal Pharmacology, College of Oriental Medicine, Kyung Hee University, Seoul, Korea.

- Tel : +82-2-961-0419・E-mail : 2020mj@hanmail.net

· 접수 : 2013년 2월 23일 · 수정 : 2013년 3월 21일 ·채택 : 2013년 3월 21일
} 
hippocampus through deleterious biochemical cascades ${ }^{10-13)}$.

In the present study, the neuroprotective effect of sesamin was investigated in global ischemia model. 4-VO model was used to induce global cerebral ischemia and reperfusion $^{14,15)}$. We also investigated the effects on microglial activation using immunohistochemistry, RT-PCR and western blot analysis for a histochemical marker of microglia (OX-42), cyclooxygenase-2 (COX-2), inducible nitric oxide (iNOS), and interleukin-1 $\beta$ (IL-1 $\beta$ ) following ischemia induction. By using $4-\mathrm{VO}$ rat model, we found that sesamin protected against neuronal cell death and suppressed microglial activation in global cerebral ischemia in rats.

\section{Materials and Methods}

\section{Sample preparation}

The sesamin used in this study was obtained from Ginseng \& Medicinal Crops Division, National Institute of Crop Science (NICS), Rural Development Administration (RDA). The sesamin was dissolved in $5.0 \%$ dimethyl sulfoxide (DMSO) and intraperitoneally (i.p.) injected in doses of $0.3,1.0,3.0$, and 10.0 $\mathrm{mg} / \mathrm{kg}$ after 0 and $90 \mathrm{~min}$ of cerebral ischemia (administration volume, $1.0 \mathrm{ml} / \mathrm{kg}$ ). A vehicle-treated group was treated with same volume of $5.0 \%$ DMSO.

\section{Animal model}

All animal procedures were conducted in accordance with the animal welfare guidelines of the Korean National Institute of Health (NIH) and the Korean Academy of Medical Sciences. Male Wistar rats (SLC, Japan) weighing between $160 \mathrm{~g}$ and $180 \mathrm{~g}$ were housed under controlled-temperature $\left(22 \pm 2 \quad{ }^{\circ} \mathrm{C}\right)$, constant-humidity, and $12 \mathrm{~h}$ light/dark cycle (lights on 07:00-19:00) conditions, with food and water available ad libitum. Transient global cerebral ischemia was induced by $4-\mathrm{VO}$ according to the method of Pulsinelli and Brierley ${ }^{14)}$.

The animals were anesthetized with isoflurane (initiated and maintained with $5.0 \%$ and $1.5 \%$ isoflurane, respectively). After the animals were positioned in stereotaxic ear bars (Kopf Instruments, Tujunga, CA, USA), the vertebral arteries at the first cervical vertebra were coagulated by using the $0.5-\mathrm{mm}$ diameter needle of an electrocoagulator. Both common carotid arteries (CCA) were then isolated and ligated via a ventral, midline cervical incision. On the following day, 10 min of 4-VO ischemia was induced through CCA occlusion by applying aneurysm clips for $10 \mathrm{~min}$. To minimize variability among animals, the following criteria were strictly applied for the 10-min ischemic period and the $20 \pm 5$ min postischemic coma (loss of righting reflex and bilateral pupil dilation). After 10 min of 4-VO, ligatures in the neck and around the CCAs were removed and the neck wound was closed with surgical clips. Body temperature was monitored and maintained at $37 \pm 0.5{ }^{\circ} \mathrm{C}$ with a heating blanket (Harvard Apparatus, Edenbridge, UK) until $6 \mathrm{~h}$ after ischemia. The sham-operated animals underwent the same surgical procedures, with the exception that the CCAs were not occluded.

\section{Histology}

At $48 \mathrm{~h}$ (for immunohistochemistry of COX-2) or 7 days (for immunohistochemistry of OX-42 and cell counting) after ischemia, the animals were anesthetized and their brains were perfusion-fixed with $4 \%$ paraformaldehyde following transcardial wash-out with heparinized $5 \%$ sodium nitrite saline. The fixed brains were cut into sections $(30-\mu \mathrm{m}$ thick for cell counting, 40- $\mu$ thick for immunohistochemistry) on a HM440E microtome (Carl Zeiss, Germany) and the sections were stained with $0.5 \%$ cresyl violet. For each animal, the neuronal cell density was measured by counting viable cells in a total of six frames $(1.0 \times 1.0 \mathrm{~mm} 2)$ of the left and right CA1 regions of three coronal sections $(\times 400$; $3.3,3.5$, and $3.7 \mathrm{~mm}$ caudal to the Bregma). The neuronal cell density is equivalent to the average number of viable cells in one frame. Cell counting was conducted by three technicians blinded to the experimental conditions.

\section{Immunohistochemistry}

Free-floating $(40 \mu \mathrm{m})$ sections were reacted with a goat polyclonal antibody against COX-2 (diluted 1:1000; Santa Cruz Biotechnology Inc., CA, USA) or a mouse polyclonal antibody against OX-42 (against the CD11b surface antigen, diluted 1:100; Serotec, Oxford, UK) overnight at room temperature. Following incubation, the sections were reacted with anti-goat or anti-mouse antibody (diluted 1:200; Vector Laboratories, CA, USA) for $60 \mathrm{~min}$ and then reacted with an avidin-biotin-peroxidase complex kit (diluted 1:50, Elite $A B C$ kit; Vector Laboratories) at room temperature for $60 \mathrm{~min}$. The avidin-biotin complex was visualized with $0.05 \% \quad 3,3^{\prime}$-diaminobenzidine (DAB, Sigma) and $0.02 \% \mathrm{H}_{2} \mathrm{O}_{2}$. 


\section{Reverse transcription-polymerase chain} reaction

At $24 \mathrm{~h}$ after ischemia, the tissues were collected and homogenized. The total RNA was extracted using easy-BLUE (iNtRon Biotechnology, Seoul, Korea) and cDNA was synthesized using a ONE-STEP mix (iNtRon Biotechnology). The PCR products were directly synthesized from $2 \mu \mathrm{g}$ of total RNA isolated from the affected hemispheres using the SuperScript one step RT-PCR system with Platinum Taq (iNtRon Biotechnology) and gene-specific primers, by following the instructions provided by the manufacturer. The reaction mixtures (iNtRon Biotechnology), consisting of $2 \mu \mathrm{g}$ of total RNA and 5 pmol primers, were incubated at $45^{\circ} \mathrm{C}$, denatured at $94^{\circ} \mathrm{C}$ for $5 \mathrm{~min}$, and then subjected to 32 amplification cycles $\left(30 \mathrm{~s}\right.$ at $94^{\circ} \mathrm{C}, 30 \mathrm{~s}$ at $45^{\circ} \mathrm{C}$, and 1 $\min$ at $70^{\circ} \mathrm{C}$ ). This was followed by a final elongation for $10 \mathrm{~min}$ at $70^{\circ} \mathrm{C}$. The PCR products were analyzed by agarose gel electrophoresis (1.5\%), stained with ethidium bromide, and scanned with a Gel-Doc image analysis system (Bio-Rad, CA, USA). The sequences of iNOS, IL-1 $\beta$ and GAPDH primers were as follows: forward and reverse primers, respectively: 5' -ACA ACG TGG AGA AAA CCC CAG GTG-3' and 5' -ACA GCT CCG GGC ATC GAA GAC C-3' for iNOS (566 bp of amplification products); $5^{\prime}$-AGA AGC TGT GGC AGC TAC CT-3' and 5' -TTG GGA TCC ACA CTC TCC AG-3' for IL-1 $\beta$ (400 bp of amplification products); 5' -GTG ATG GGT GTG AAC CAC GAG$3^{\prime}$ and $5^{\prime}$-CAG TGA GCT TCC CGT TCA GCT-3' for GAPDH (295 bp of amplification products).

\section{Western blot analysis}

At $48 \mathrm{~h}$ after ischemia, the tissues were lysed in triple-detergent lysis buffer $(50 \mathrm{mM}$ Tris-HCl, $\mathrm{PH}$ 8.0; $150 \mathrm{mM} \mathrm{NaCl} ; 0.1 \%$ sodium dodecyl sulfate (SDS); $1 \% \mathrm{NP}-40 ; 0.02 \%$ sodium azide; $0.5 \%$ sodium deoxycholate; and $1 \mathrm{mM}$ phenylmethylsulfonylfluoride). A protein sample (30 mgforeach) was separated by $8 \%$ SDS-polyacrylamide gel electrophoresis (PAGE) and transferred to a Hybond ECL nitrocellulose membrane (Amersham Pharmacia Biotech, Bucking hamshire, UK). The membrane was blocked with 5\% skimmed milk and incubated with the primary antibody and horseradish peroxidase (HRP)-conjugated secondary antibody (Santa Cruz Biotechnology Inc., CA, USA). The blots were detected by a West-Zol ${ }^{\mathrm{TM}}$ plus western blot detection system (iNtRon Biotechnology, Korea).

\section{Statistical analysis}

Data are expressed as the mean \pm SEM. Statistical analysis was performed using a one-way ANOVA, followed by Dunnett' s posttest to compare all data with control, with the sham-operated or vehicle-treated group. Data was considered to be significant when the $P$ value was less than 0.05 .

\section{Results}

\section{Sesamin inhibits ischemia-induced neuronal}

\section{cell death}

To investigate whether sesamin has neuroprotective in global cerebral ischemia, we performed 4-VO with rats and measured the neuronal cell density in the CA1 hippocampal region at 7 days after $10 \mathrm{~min}$ of ischemia.

In the sham-operated group, the neuronal density in the CA1 region was normal (Fig. 1A) and most of the pyramidal neurons in the CA1 region exhibited an intact morphology and no damaged cells (Fig. 1a). In the vehicle-treated group, the neuronal density was reduced (Fig. 1B) and the neurons in the CA1 region exhibited a shrunken morphologically and coagulation (Fig. 1b). The group treated with $3.0 \mathrm{mg} / \mathrm{kg}$ sesamin exhibited an increase in neuronal density (Fig. 1C) and, compared with the vehicle-treated group, an increased number of intact pyramidal neurons in the CA1 region (Fig. 1c).

Ten minutes of ischemia reduced the number of neurons in the CA1 region to $24.3 \pm 3.9$ cells $/ \mathrm{mm}^{2}$ compared with the sham-operated group (310.4 \pm 7.2 cells $/ \mathrm{mm}^{2}$ ). Sesamin conferred neuroprotection by markedly reducing the number of damaged pyramidal cells in the CA1 subfield. The neuroprotective effect of sesamin was dose dependent in the $0.3-3.0 \mathrm{mg} / \mathrm{kg}$ treated groups.

Sesamin at $0.3,1.0,3.0$, and $10.0 \mathrm{mg} / \mathrm{kg}$ resulted in $100.6 \pm 12.9,110.4 \pm 15.6,146.0 \pm 17.1$ and $110.5 \pm 19.8$ cells $/ \mathrm{mm}^{2}$, respectively ( $\left.\mathrm{P}<0.01-0.001\right)$. They reduced the number of damaged pyramidal cells in the CA1 subfield and the $3.0 \mathrm{mg} / \mathrm{kg}$-treated group exhibited a $42.6 \%$ neuroprotective effect compared with the sham-operated group (Fig. 2).

These results clearly indicate that sesamin exhibits a neuroprotective effect in global cerebral ischemia. 


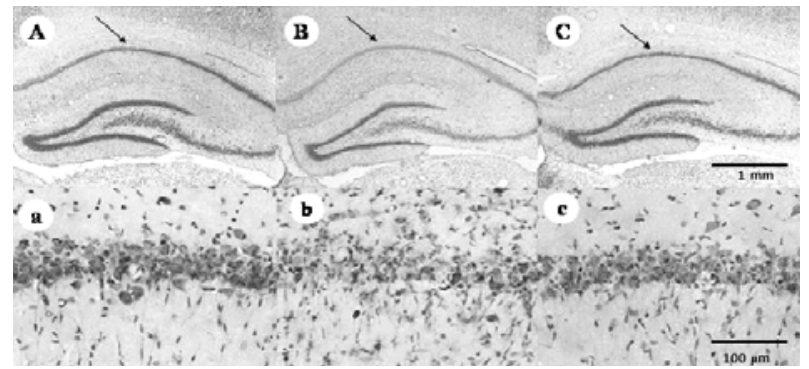

Fig. 1. Typical photomicrographs of the hippocampus in the sham-operated, control, and sesamin-treated groups at 7 days after ischemia. Cresyl violet staining of coronal brain sections of the dorsal hippocampus revealed selective, delayed neuronal cell loss in the hippocampal CA1 region induced by a 10-min ischemia. A, a; in the sham-operated rats, arrows indicate the tracks of the CA1 pyramidal neurons. The majority of pyramidal cells in the CA1 region exhibit unaltered staining properties. B, b; in the vehicle treated rats, arrow indicates the reduced staining intensity of the pyramidal cell layer. The neuronal changes were restricted to the CA1 subfield. The damage could be characterized by the coagulative cell change of the pyramidal neurons and pronounced gliosis. C, c; the sesamin $(3.0 \mathrm{mg} / \mathrm{kg}$, i.p.)-treated group exhibited a marked reduction in the number of irreversibly damaged pyramidal cells in the CA1 region. The scale bars are 1 $\mathrm{mm}(\mathrm{A}, \mathrm{B}$, and $\mathrm{C})$ and $100 \mu \mathrm{m}(\mathrm{a}, \mathrm{b}$, and $\mathrm{C})$.

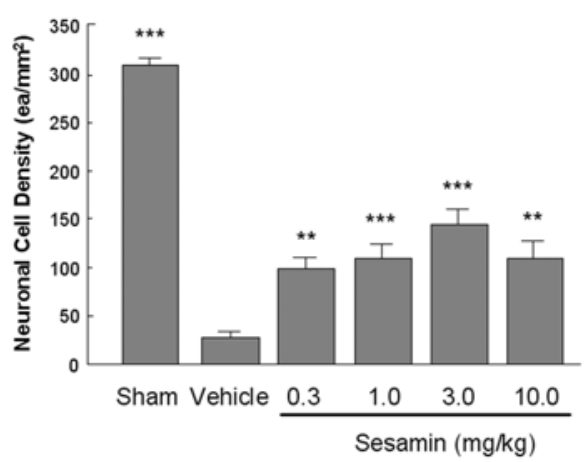

Fig. 2. Neuroprotective effects of sesamin at 7 days after global ischemia-reperfusion. Animals were intraperitoneally administered sesamin $(0.3,1.0,3.0$, and $10.0 \mathrm{mg} / \mathrm{kg})$ at 0 and $90 \mathrm{~min}$ after a 10-min ischemia, $\mathrm{n}=3-8$ per group. Results represent average normal-appearing CA1 pyramidal neuronal counts over a $1 \mathrm{~mm}$ length of both left and right hemispheres of three sections. Values are expressed as the means \pm SEM. Mean data points were analyzed by a one-way analysis of variance (ANOVA), followed by Dunnett' $s$ post hoc test to compare all data with the vehicle treated group ( ${ }^{* *} \mathrm{P}\left\langle 0.01,{ }^{* * *} \mathrm{P}<0.001\right)$.

\section{Sesamin inhibits $\mathrm{OX}-42$ upregulation}

To study whether sesamin affected microglial activation in global cerebral ischemia, immunohistochemical analysis were used with a histochemical marker of microglia, OX-42. The vehicle-treated control group exhibited a high density of OX-42 positive cells around the CA1 region at 7 days after ischemia (Fig. 3B, b). Conversely, the sham-operated group exhibited a low density (Fig. $3 \mathrm{~A}$, a). Sesamin reduced the density of OX-42 positive cells compared with vehicle-treated group (Fig. 3C, c). This suggests that sesamin inhibits OX -42 upregulation and downregulates microglial activation in global cerebral ischemia.

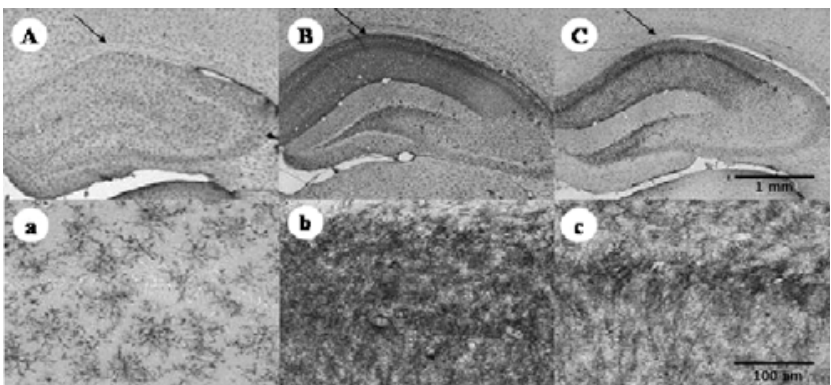

Fig. 3. Effect of sesamin on microglial activation in 4-VO rats. Microglial activation was identified using an OX-42 antibody at 7 days after ischemia. Activation of microglia in the vehicle treated group $(\mathrm{B}, \mathrm{b})$ was strongly induced compared to the sham group $(A, a)$. On the other hand, in the sesamin-treated $(3.0 \mathrm{mg} / \mathrm{kg}$ ) group (C, C), microglial activation was significantly suppressed. The scale bars are $1 \mathrm{~mm}(\mathrm{~A}, \mathrm{~B}$, and $\mathrm{C})$ and $100 \mu \mathrm{m}(\mathrm{a}, \mathrm{b}$, and c). Data was shown typical result from three independent experiments.

\section{Sesamin inhibits $\mathrm{COX}-2$ protein}

\section{expression}

To study whether sesamin reduce neurotoxicity mediated by inflammation in global cerebral ischemia, we observed COX-2 immunoreactivity by immunohistochemistry. A low level of basal COX-2 immunoreactivity occurred in neurons of the pyramidal cell and granule cell layers in the hippocampus of sham-operated group (Fig. 4A, a). $48 \mathrm{~h}$ after $10 \mathrm{~min}$ of global cerebral ischemia induced upregulated COX-2 expression in the CA1 to CA3 pyramidal neurons compared with sham-operated group (Fig. 4B, b). Intraperitoneal injection of sesamin $3.0 \mathrm{mg} / \mathrm{kg}$ downregulated COX-2 expression in the CA1 region compared with vehicle-treated group (Fig. 4C, c). Thus, sesamin reduces the neuronal damage mediated by inflammation in global cerebral ischemia because sesamin inhibits COX-2 expression in the hippocampus.

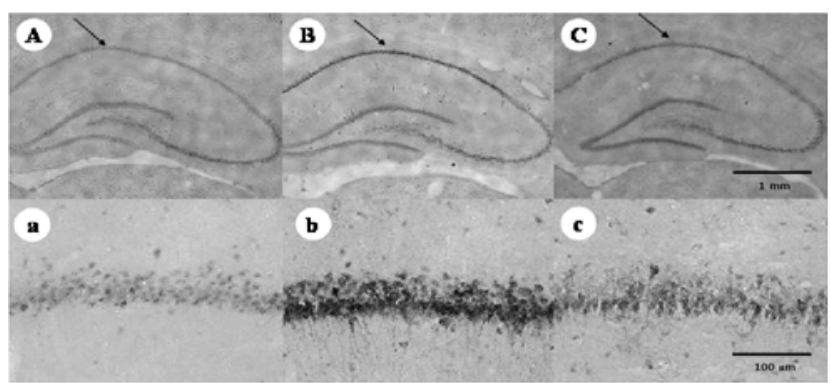

Fig. 4. Effect of sesamin $(3.0 \mathrm{mg} / \mathrm{kg})$ on $\mathrm{COX}-2$ immunoreactivity at $48 \mathrm{~h}$ after global ischemia-reperfusion. Hippocampal sections exhibited COX-2 (1:200) immunohistochemistry in the pyramidal neurons of the CA1 region. $A$, a; sham-operated rats. $B, b$; vehicle treated rats. COX-2 was increased in the pyramidal neurons after global ischemia-reperfusion. C, c; sesamin-treated $(3.0 \mathrm{mg} / \mathrm{kg}$ ) rats, COX-2 decreased compared to the vehicle treated rats. The scale bars are $1 \mathrm{~mm}$ (A, B, and C) and 100 $\mu \mathrm{m}$ ( $\mathrm{a}, \mathrm{b}$, and $\mathrm{c})$. Data was shown typical result from three independent experiments. 


\section{Sesamin inhibits iNOS and $\mathrm{IL}-1 \beta$ expressions}

To study whether sesamin reduces neuronal damage mediated by neurotoxic nitrogen intermediates and proinflammatory cytokines in global cerebral ischemia, we measured iNOS and IL-1 $\beta$ mRNA expressions and immunoreactivity using RT-PCR and western blot analysis. iNOS and IL-1 $\beta$ mRNA expressions were upregulated at $24 \mathrm{~h}$ after global ischemia compared with the sham-operated group. The protein expressions were investigated by Western blot analysis at $48 \mathrm{~h}$ after ischemia. iNOS and IL-1 $\beta$ expressions were upregulated compared with sham-operated group. On the other hand, Sesamin at 1.0 and $3.0 \mathrm{mg} / \mathrm{kg}$ reduced the immunoreactivity of iNOS and IL-1 $\beta$. 3.0 $\mathrm{mg} / \mathrm{kg}$ treated group showed more inhibition than 1.0 $\mathrm{mg} / \mathrm{kg}$ treated group (Fig. 5). The results indicate that sesamin reduces the neuronal damage mediated by microglia-derived neurotoxic or proinflammatory factors including $\mathrm{NO}$ and $\mathrm{IL}-1 \beta$ in global cerebral ischemia.
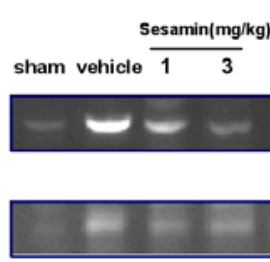

IL-1B
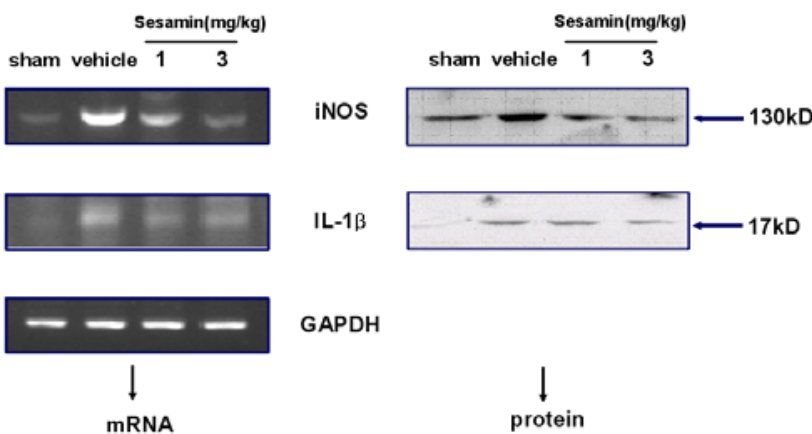

GAPDH

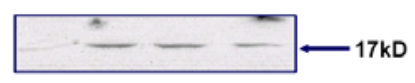

Fig. 5. Effect of sesamin on iNOS and $\mathrm{L}-1 \beta$ expressions in $4-\mathrm{VO}$ rats. Left; iNOS and $\mathrm{L}-1 \beta \quad \mathrm{mRNA}$ expressions were determined using RT-PCR at $24 \mathrm{~h}$ after 4-VO. Right; NOS and $\|-1 \beta$ protein expression was determined using western blot analysis at $48 \mathrm{~h}$ after 4-VO. Lane 1, sham; Lane 2, vehicle; Lane 3, $1.0 \mathrm{mg} / \mathrm{kg}$ sesamin treatment; Lane $4,3.0 \mathrm{mg} / \mathrm{kg}$ sesamin treatment. Data was shown typical result from three independent experiments.

\section{Discussion}

The major findings in this study are that sesamin treatment after the onset of ischemia protected hippocampal CA1 neuronal damage in the transient global ischemia rat model and inhibited the expression of $\mathrm{OX}-42, \mathrm{COX}-2$, iNOS and IL-1 $\beta$. To our knowledge, this is the first report to investigate the neuroprotective effect of sesamin against to global cerebral ischemia in rats.

Intraperitoneal injection of sesamin markedly reduced neuronal cell death in the hippocampal CA1 region in 4-VO rats. This result is consistent with previous in vitro studies which reported that sesamin $50 \mu \mathrm{M}$ showed $30 \%-40 \%$ of protective effects on OGD induced $\mathrm{PC} 12$ cell death ${ }^{6)}$. The result suggests that sesamin has neuroprotective effect in global cerebral ischemia-reperfusion injury in rats.

4-VO induces microglial activation in the rat hippocampus ${ }^{16)}$. OX-42, a histochemical marker of microglia, was upregulated at 7 days after ischemia, and treatment with sesamin inhibited OX-42 upregulation. Microglial activation is characterized by the release of free radicals and the expression of myeloid markers with morphological transformation ${ }^{17)}$, and induces iNOS and COX-2 expression so that produce several potentially neurotoxic substances, including NO and prostaglandins, consequently leading to death of neurons. Microglial activation also produces proinflammatory cytokines, including IL-1 $\beta$, IL-6, and $\mathrm{TNF}-\alpha$ which may exert a direct toxicity on neurons ${ }^{18-20)}$. The result suggests that the neuroprotective effect of sesamin exerts by inhibiting microglial activation in global ischemia.

COX-2, a prostanoid-synthesizing enzyme, is a mitogen-inducible isoform whose reaction products are responsible for many of the cytotoxic effects of inflammation $^{21,22)}$. COX-2 was downregulated by treatment with $3.0 \mathrm{mg} / \mathrm{kg}$ sesamin in the CA1 region at $48 \mathrm{~h}$ after ischemia. COX-2 expression, induced by microglial activation, is initiated $12 \mathrm{~h}$ after ischemia, peaks at $24 \mathrm{~h}$, and remains up to $72 \mathrm{~h}$ after global cerebral ischemia in the pyramidal neurons of the CA1 region $^{23)}$. While COX-2 over-expressing mice have larger infarcts after experimental stroke ${ }^{24)}$, disruption of the COX-2 gene provides protection against ischemic brain injury in rodents ${ }^{25)}$. In addition, selective pharmacologic inhibition of COX-2 activity has proven to be a potential therapeutic target against stroke in animal models ${ }^{21,22)}$. The present result suggests that sesamin reduce the neuronal damage through COX-2 inhibition in global ischemia.

Following brain ischemia, upregulation of iNOS leads to an overproduction of $\mathrm{NO}$ in neurons, endothelial cells, and microglia ${ }^{26,27)}$. The production of $\mathrm{NO}$ is attributed to the formation of toxic peroxynitrate, and this causes neuronal damage after brain ischemia $^{28,29)}$. NO involves in the process of neuronal damage following cerebral ischemia ${ }^{21)}$. Especially, NO overproduction is induced by microglial activation ${ }^{18,19)}$. Inhibitors of NOS have resulted in significant neuroprotection $^{30,31)}$. In this study, sesamin reduced mRNA expression and immunoreactivity of iNOS. The result was consistent with the previous study that sesamin inhibits NO production, iNOS mRNA and 
protein expression in LPS-stimulated BV-2 cells ${ }^{7)}$. The present data suggests that sesamin inhibit iNOS mRNA and protein expressions in conjunction with the inhibitory effect on microglial activation.

The proinflammatory cytokine $\mathrm{IL}-1 \beta$ is known to be the major microglial signal that promotes the cascade of glial cell reactions ${ }^{32)}$. IL-1 $\beta$ represents a crucial mediator of neurodegeneration induced by traumatic brain injury ${ }^{33)}$. Focal brain ischemia in MCAo-reperfusion rats results in a significant induction of IL-1 $\beta \mathrm{mRNA}^{34-36)}$. In the current study, IL-1 $\beta$ mRNA and protein expressions were upregulated at $24 \mathrm{~h}$ and at $48 \mathrm{~h}$ after $4-\mathrm{VO}$, respectively, whereas in the sesamin-treatment group, these expressions were inhibited. The result suggests that sesamin reduces the neuronal damage mediated by microglia-derived proinflammatory factor $\mathrm{IL}-1 \beta$ in global cerebral ischemia.

\section{Conclusion}

In this study for evaluating neuroprotective effects of sesamin against in vivo global cerebral ischemia model, the results were as follows:

1. Sesamin has neuroprotective effect in global cerebral ischemia-reperfusion injury in rats.

2. Sesamin inhibits $\mathrm{OX}-42$ upregulation in global cerebral ischemia.

3. Sesamin reduce the neuronal damage through COX -2 inhibition in global ischemia.

4. Sesamin reduce the immunoreactivity of iNOS and IL-1 $\beta$ that correlated with microglia-derived neurotoxic or proinflammatory factors in global cerebral ischemia.

Together, this study indicates that sesamin protects neuronal cell death through inhibition of microglial activation or the production of neurotoxic metabolites and proinflammatory mediators by microglia such as COX-2, iNOS and IL-1 $\beta$ in global cerebral ischemia. The intake of sesame seed as a rich source of sesamin may provide neuroprotection.

\section{Acknowledgement}

This study was supported by a grant of the Korean Health Technology R\&D Project, Ministry of Health \& Welfare, Republic of Korea (B110072).

\section{References}

1. Park SH, Ryu SN, Bu Y, Kim H, Simon JE, Kim KS. Antioxidants components as potential neuroprotective agents in sesame (Sesamum indicum L.). Food Rev Int. $2010 ; 26$ : 103-21.

2. Ryu SR, Lee JI, Kang SS, Choi CY. Quantitative analysis of antioxidants in Sesame seed. Korean J Crop Sci. 1992 ; 37 : 377-82.

3. Cooney RV, Custer LJ, Okinaka L, Franke AA. Effects of dietary sesame seeds on plasma tocopherol levels. Nutr Cancer. 2001 ; 39 : 66-71.

4. Khan MM, Ishrat $\mathrm{T}$, Ahmad $\mathrm{A}$, Hoda MN, Khan MB, Khuwaja G, Srivastava P, Raza SS, Islam F, Ahmad S. Sesamin attenuates behavioral, biochemical and histological alterations induced by reversible middle cerebral artery occlusion in the rats. Chem Biol Interact. 2010 ; 183 : 255-63.

5. Ohnishi M, Monda A, Takemoto R, Matsuoka Y, Kitamura C, Ohashi K, Shibuya H, Inoue A. Sesamin suppresses activation of microglia and p44/42 MAPK pathway, which confers neuroprotection in rat intracerebral hemorrhage. Neurosci. 2013 ; 232 : 45-52.

6. Hou RC, Huang HM, Tzen JT, Jeng KC. Protective effects of sesamin and sesamolin on hypoxic neuronal and PC12 cells. J Neurosci Res. 2003b ; $74: 123-33$.

7. Hou RC, Chen HL, Tzen JT, Jeng KC. Effect of sesame antioxidants on LPS-induced NO production by BV2 microglial cells. Neuroreport . 2003a ; 14 : $1815-9$.

8. Jeng KC, Hou RC, Wang JC, Ping LI. Sesamin inhibits lipopolysaccharide-induced cytokine production by suppression of p38 mitogen-activated protein kinase and nuclear factor-kappaB. Immunol Lett. $2005 ; 97$ : 101-6.

9. Petito CK, Feldmann E, Pulsinelli WA, Plum F. Delayed hippocampal damage in humans following cardiorespiratory arrest. Neurology. 1987 ; 37 : 1281-6.

10. Pulsinelli WA, Brierley JB, Plum F. Temporal profile of neuronal damage in a model of transient forebrain ischemia. Ann Neurol. 1982 ; 11 : 491-8.

11. Kirino T. Delayed neuronal death in the gerbil hippocampus following ischemia. Brain Res. 1982 ; 239 : 57-69.

12. Nitatori T, Sato N, Waguri S, Karasawa Y, Araki H, Shibanai K, Kominami E, Uchiyama Y. Delayed neuronal death in the CA1 pyramidal cell layer of the gerbil hippocampus following transient ischemia is apoptosis. J Neurosci. 1995 ; 15 : 
1001-11.

13. Niwa M, Hara A, Iwai T, Wang S, Hotta K, Mori $\mathrm{H}$, Uematsu T. Caspase activation as an apoptotic evidence in the gerbil hippocampal CA1 pyramidal cells following transient forebrain ischemia. Neurosci Lett. 2001 ; 300 : 103-6.

14. Pulsinelli WA, Brierley JB. A new model of bilateral hemispheric ischemia in the unanesthetized rat. Stroke. $1979 ; 10$ : 267-72.

15. Furlow TW, Jr.. Cerebral ischemia produced by four-vessel occlusion in the rat: a quantitative evaluation of cerebral blood flow. Stroke. 1982 ; $13: 852-5$.

16. Stephenson DT, Schober DA, Smalstig EB, Mincy RE, Gehlert DR, Clemens JA. Peripheral benzodiazepine receptors are colocalized with activated microglia following transient global forebrain ischemia in the rat. J Neurosci. $1995 ; 15$ : 5263-74.

17. Ladeby R, Wirenfeldt M, Garcia-Ovejero D, Fenger C, ssing-Olesen L, Dalmau I, Finsen B. Microglial cell population dynamics in the injured adult central nervous system. Brain Res Brain Res Rev. 2005 ; 48 : 196-206.

18. Chao CC, Hu S, Molitor TW, Shaskan EG, Peterson PK. Activated microglia mediate neuronal cell injury via a nitric oxide mechanism. J Immunol. 1992 ; 149 : 2736-41.

19. McMillian MK, Vainio PJ, Tuominen RK. Role of protein kinase $\mathrm{C}$ in microglia-induced neurotoxicity in mesencephalic cultures. J Neuropathol Exp Neurol. 1997 ; 56 : 301-7.

20. Choi SH, Joe EH, Kim SU, Jin BK. Thrombin-induced microglial activation produces degeneration of nigral dopaminergic neurons in vivo. J Neurosci. $2003 ; 23$ : 5877-86.

21. Nakayama M, Uchimura K, Zhu RL, Nagayama T, Rose ME, Stetler RA, Isakson PC, Chen J, Graham SH. Cyclooxygenase-2 inhibition prevents delayed death of CA1 hippocampal neurons following global ischemia. Proc Natl Acad Sci U S A. 1998 ; 95 : 10954-9.

22. Nogawa S, Zhang $\mathrm{F}$, Ross ME, Iadecola C. Cyclo-oxygenase-2 gene expression in neurons contributes to ischemic brain damage. J Neurosci. $1997 ; 17$ : 2746-55.

23. Koistinaho J, Koponen S, Chan PH. Expression of cyclooxygenase-2 mRNA after global ischemia is regulated by AMPA receptors and glucocorticoids. Stroke. 1999 ; 30 : 1900-5.

24. Dore S, Otsuka T, Mito T, Sugo N, Hand T, Wu L, Hurn PD, Traystman RJ, Andreasson K. Neuronal overexpression of cyclooxygenase-2 increases cerebral infarction. Ann Neurol. 2003 ; 54 : 155-62.
25. Iadecola C, Niwa K, Nogawa S, Zhao X, Nagayama M, Araki E, Morham S, Ross ME. Reduced susceptibility to ischemic brain injury and $\mathrm{N}$-methyl-D-aspartate-mediated neurotoxicity in cyclooxygenase-2-deficient mice. Proc Natl Acad Sci U S A. 2001 ; 98 : 1294-9.

26. Tominaga T, Sato S, Ohnishi T, Ohnishi ST. Potentiation of nitric oxide formation following bilateral carotid occlusion and focal cerebral ischemia in the rat: in vivo detection of the nitric oxide radical by electron paramagnetic resonance spin trapping. Brain Res. 1993 ; 614 : 342-6.

27. Samdani AF, Dawson TM, Dawson VL. Nitric oxide synthase in models of focal ischemia. Stroke. 1997 ; 28 : 1283-8.

28. Beckman JS, Beckman TW, Chen J, Marshall PA, Freeman BA. Apparent hydroxyl radical production by peroxynitrite: implications for endothelial injury from nitric oxide and superoxide. Proc Natl Acad Sci U S A. 1990 ; 87 : 1620-4.

29. Iadecola $\mathrm{C}$, Zhang $\mathrm{F}$, Xu X. Inhibition of inducible nitric oxide synthase ameliorates cerebral ischemic damage. Am J Physiol. 1995 ; 268 : R286-92.

30. Bal-Price A, Brown GC. Inflammatory neurodegeneration mediated by nitric oxide from activated glia-inhibiting neuronal respiration, causing glutamate release and excitotoxicity. J Neurosci. $2001 ; 21$ : 6480-91.

31. Munch G, Gasic-Milenkovic J, Dukic-Stefanovic S, Kuhla B, Heinrich K, Riederer P, Huttunen HJ, Founds H, Sajithlal G. Microglial activation induces cell death, inhibits neurite outgrowth and causes neurite retraction of differentiated neuroblastoma cells. Exp Brain Res. 2003 ; 150 : 1-8.

32. Schubert $P$, Rudolphi $K$. Interfering with the pathologic activation of microglial cells and astrocytes in dementia. Alzheimer Dis Assoc Disord. 1998 ; 12 Suppl 2 : S21-8.

33. Rothwell N. Interleukin-1 and neuronal injury: mechanisms, modification, and therapeutic potential. Brain Behav Immun. 2003 ; 17 : 152-7.

34. Liu T, McDonnell PC, Young PR, White RF, Siren AL, Hallenbeck JM, Barone FC, Feurestein GZ. Interleukin-1 beta mRNA expression in ischemic

35. Buttini M, Sauter A, Boddeke HW. Induction of interleukin-1 beta mRNA after focal cerebral ischaemia in the rat. Brain Res Mol Brain Res. 1994 ; 23 : 126-34.

36. Berti R, Williams AJ, Moffett JR, Hale SL, Velarde LC, Elliott PJ, Yao C, Dave JR, Tortella FC. Quantitative real-time RT-PCR analysis of inflammatory gene expression associated with ischemia-reperfusion brain injury. $\mathrm{J}$ Cereb Blood Flow Metab. 2002 ; 22 : 1068-79. 